\title{
Policy Responses and Social Solidarity Imperatives to Respond the COVID-19 Pandemic Socioeconomic Crises in Ethiopia
}

\author{
Kiflie Worku Angaw (1D \\ Dilla University, College of Business and \\ Economics, Department of Public \\ Administration and Development \\ Management, Dilla, Ethiopia
}

Background: The study evaluated the public administration's policy responses and imperatives of social solidarity to reduce the havoc caused by the COVID-19 pandemic. The pandemic has not only posed a serious health threat but also brought economic, sociocultural and psychological crises to human beings all over the world. The study was conducted to give a clear picture of the COVID-19 pandemic socioeconomic crises in Ethiopia and policy responses given as well as the imperatives of social organizations in Ethiopia to tackle these challenges.

Purpose: This article aimed to explore the extent to which the COVID-19 pandemic impacted the socio-economic activities of Ethiopia and evaluate the effectiveness and limitations of the policy response given by the public administration vis-à-vis the role of social solidarity to reduce the calamity of the pandemic.

Methods: Qualitative research approach has been used and data were analyzed using narration, description, and exploration analysis method.

Results: The findings of the study revealed that the policy responses given by the public administration and the solidarity of social organizations played great role in minimizing the socio-economic crises that the pandemic entailed. Policy responses had limitations and lack of appropriate institutional implementation platforms.

Conclusion: The policy responses given by the public administration to alleviate the socioeconomic crises caused by the pandemic have both success and limitations. Social organizations played a paramount role in alleviating the COVID-19 socio-economic crises on vulnerable and disadvantaged groups.

Keywords: COVID-19, pandemic, policy response, social solidarity, socioeconomic crises

\section{Introduction}

The COVID 19 pandemic has been taking lives of people from all over the world and declared as global pandemic by World Health Organization. The world had so far experienced severe epidemic diseases such as the "Spanish influenza" of 1918, the "Asian flu" of 1957, the "Hong Kong flu" of 1968, the Severe Acute Respiratory Syndrome (SARS) in 2002, the N1H1 ("bird flu") in 2009, the Middle East Respiratory Syndrome (MERS) in 2012, the Ebola in 2013, and the COVID-19 pandemic in 2020. ${ }^{1-3}$ Of these epidemics, the COVID-19 pandemic is the largest in terms of the amount of area it covered and people it affected. ${ }^{3,29}$ The pandemic is the worst health crisis that the Earth planet has faced in the last 75 years United Nations. ${ }^{29}$ Scientists have not yet fully understood the full impact the
Correspondence: Kiflie Worku Angaw

Dilla, Ethiopia

Tel +25I-9l I-59-7I-94

Email macrown55@gmail.com 
COVID-19 pandemic had on the global and regional socio-economic development. ${ }^{3}$ The pandemic significantly heightens all existing inequalities and these inequalities severely affect vulnerable segments of the societies particularly the developing economies like Ethiopia. The existing study aimed to explore the extent of the socioeconomic crises of the pandemic and evaluate the public administration's policy response measures taken by the government and the role of social organizations to respond to the havoc of COVID-19 pandemic entailed in Ethiopia.

\section{Background and Research Setting}

The world is in the most severe pandemic in living memory. ${ }^{29}$ Scientists dubbed the pandemic's source Severe Acute Respiratory Syndrome Coronavirus-2 (SARS-CoV-2), but it is more commonly referred to by the label assigned the disease it causes: coronavirus disease 2019 "COVID-19" spreading rapidly at a historic scale with unprecedented impacts. ${ }^{28}$ The impact of the COVID-19 pandemic goes beyond mortality and morbidity. $^{21,22}$ Its impact on global and regional growth has not yet been properly understood and the worst is yet to come. $^{8}$ Different estimations indicate that socioeconomic crises will follow and the pandemic has affected the economic activities of the world. The top ten global economies that account for $60 \%$ of global supply and demand (GDP), $65 \%$ of manufacturing, and $41 \%$ of export earning of the global economy have been severely affected. ${ }^{3}$ Similarly, the Ethiopian economy will face a $\$ 1.3 \mathrm{Bn}(2.2 \%)$ of GDP loss at the low base scenario, and under the severe prolonged duration of the pandemic the economy will lose $\$ 4.09 \mathrm{Bn}(6.7 \%)$ of national GDP. Among others, the services and manufacturing sectors will be the most highly affected. 5,11,31 Furthermore, UNICEF estimated that the COVID-19 pandemic will shrink the Ethiopian economy by $2.9 \%$ only in $2020 .^{28}$ The pandemic has caused serious human suffering, hit-back the economy and disrupted service and construction sectors. ${ }^{4,13}$

The world economies and state authorities provide mechanisms to respond the pandemic, governments around the world as policy responses put in place lockdown and restrict the shipment of goods/service, and people to the averse immediate transmission of the pandemics. ${ }^{13}$ These restrictions severely affected business and social interactions worldwide. ${ }^{29} \mathrm{~A}$ study ${ }^{28}$ presented, one-third of the world's population has been subjected to social restrictions and stay-at-home orders. There has been a widespread loss of income and deeper levels of poverty due to the pandemic and big impact on service, tourism, and the sizeable self-employed sectors. ${ }^{31}$ The COVID-19 pandemic has made visible to the world the contributions of the informal sectors, unpaid labor of women and girls to the development of global economies and maintenance of our daily lives. ${ }^{12}$ During this pandemic, women and girls are taking care of the children who are staying at home because schools are closed, the old, and the sick members of their families. ${ }^{3}$

The magnitude of poverty in Ethiopia is the highest even before the COVID-19 pandemic outbreak. According to ${ }^{12,31} 81.3 \%$ of the Ethiopian population is multidimensionality poor among this $22 \%$ of the population is extremely poor, and 19\% face problem of food shortage. This means even before the outbreak of the pandemic, the condition of life for the majority of Ethiopians is already precarious. $^{11,13}$ From this we can understand that the emergent of the pandemic has multiplied the risk of the vulnerable groups. The pandemic together with other reasons increased the global Fragile State Index (FSI) rank of Ethiopia from 21st (2019) to 23rd (2020) out of 180 countries. Furthermore, social inequality worsened and security apparatus indicators also showed decline. where the economy indexes declined from 6.4 before COVID-19 2019 to 6.1 in the $2020 .^{18}$

The COVID-19 pandemic outbreak impacts not only the previously vulnerable groups of the society but also to the previously economically invulnerable and extended beyond the conventional border of disadvantageous groups. Though the COVID-19 pandemic is a global crisis affecting the whole world, its impacts became more visible and riskier to developing economies. ${ }^{28}$ Africa is facing a heavy burden of socio-economic crises. Currently, the health, economic, and social institutions in Africa are overstretched even before the full burst of the pandemic. ${ }^{1,11,13}$ For example, according to the estimation of the Ethiopian Job Creation Commission, Ethiopia has suffered 14\% job loss in the service sector alone due to the COVID-19 pandemic. ${ }^{11,12,32}$ The pandemic highly impacted elders, unemployed youths, informal sector operators, children, and vulnerable families. The UNICEF reported that $48 \%$ of Africans are impacted by the COVID-19 pandemic. Estimated 22 million Africans are living in extreme poverty aggravated by the stay-at-home restrictions imposed to alleviate the pandemic. ${ }^{29}$ Accordingly, the Addis Ababa city administration estimates that there are around 50,000 homeless individuals in the capital. ${ }^{28}$ Developing economies like Ethiopia do not have enough budget to provide social 
security to these vulnerable. In such situations, social organizations and non-state actors play an important role. Therefore, this article rigorously evaluated the policy response the public administration gave and the role of social organizations to alleviate the socio-economic impacts of the pandemic in Ethiopia.

\section{Methods and Materials}

In this study, a qualitative research approach was employed. The qualitative design provides ample opportunities to answer multiple quests of the research. Therefore, it is convenient to collect data concerning the COVID-19 pandemic, its socioeconomic crises and responding strategies applied in Ethiopia using narrative (what happened previously), descriptive (what did happen), empirical pieces of evidence, predictive (what will happen), normative (what should happen), and/or explanatory (what made this happen) analysis method. ${ }^{20,34}$ This research design was chosen to scrutinize the situation of the COVID-19 pandemic in the Ethiopian contexts. Literature was reviewed from journals, policy briefs, press releases, and different sources. Data were collected by inclusion and exclusion criteria from published articles specific to COVID-19. Data from the Federal Ministry of Finance, Information Network Security Agency (INSA), National COVID-19 database (https://www.covid19.et/covid-19/), government press release, media briefs, unpublished reports, and relevant COVID-19 articles published since January 2020 were collected. Data were collected from Google scholar and other sources using simple search (blind searching), systematic search (identifying, selecting, and synthesizing published resources on COVID-19), and thread or snowballing searching technique (using references listed in relevant publications leads to other relevant publications). Finally, data were synthesized and analyzed qualitatively thematic analysis method.

\section{Literature Review}

The COVID-19 pandemic brought forceful policy reaction for irrespective globalization flourishment of 21st C. Global mobility was disconnected and de-globalization policy reactions followed. ${ }^{3}$ Globalization, technological advancement, and prudent global business sophistications entail businesses and countries to work together irrespective of the geographic distance to maximize competitive advantage. ${ }^{9}$ However, the outbreak of the COVID-19 pandemic disrupted this connection and severely affected the service, travel, hospitality and tourism sectors, as well as manufacturing industries. ${ }^{8,27}$
Most of global companies around the world and countries have switched and disconnected their industrial relationships exception of Information Communication Technology (ICT) sector and followed stay disconnected from the rest of the world which would be termed as a deglobalization policy response by forcing citizens to stay at home. ${ }^{8,24,27,32}$ The government of Ethiopia reinforced COVID-19 response efforts coordination mechanisms through an Emergency Operation Center and found out well-organized national response. $^{35}$ It established four different levels of coordination: (a) National Disaster Risk Management Council chaired by the deputy prime minister, (b) Public Health Emergency Management (PHEM) incorporated a multisectorial national task force chaired by the Minister of Health, (c) The PHEM technical task force that has been managed by the Director-General of Ethiopian Public Health Institute (EPHI); and (d) PHEM Technical unit diode by the national incident manager. ${ }^{35}$

\section{Findings and Discussion}

The impact of the pandemic is multidimensional. Besides the health crisis, it affected the world economy, risked individual's daily livelihood, and increased the incidence of poverty. ${ }^{27}$ Due to these reasons, global public administration faced unprecedented uncertainties concerning the socioeconomic wellbeing of its citizens. ${ }^{30}$ Since then, countries, international and national organizations around the world took different reactions to averse the risks of the pandemic. This section provides a detailed discussion on the Ethiopian public administration policy response alternatives and the paramount role of social organizations as an avenue of social solidarity in response to the COVID-19 socio-economic crises. Many African countries are criticized for simply copying policy responses of developed economies instead of coming up with new policies that serve best in their contexts. ${ }^{14}$ The Ethiopian policy response alternatives novelty and its relevance and effectiveness of Ethiopia also has been highlighted. The 5th September 2020 data (Figure 1) shows that the existing infection ratio of total laboratory tests in Ethiopia is $5.64 \%$. It also reveals that $36.15 \%$ of the infected people recovered and the death rate is $0.15 \%$. The total population ratio of the country infection by the COVID-19 is $0.9 \%$.

\section{The Socioeconomic Impact of COVID-19 in Ethiopia}

The majority of Ethiopia's population young population. The recent population projection shows the estimated population is 


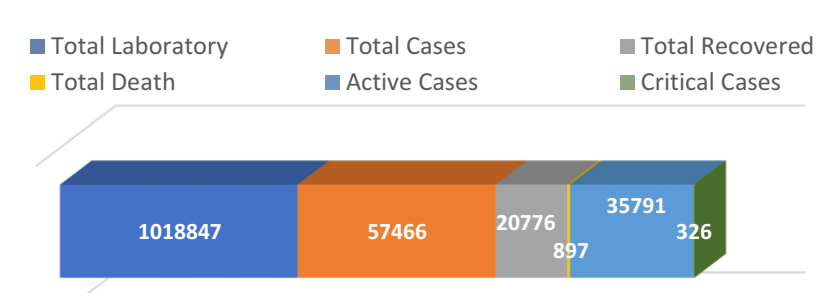

COVID19 in Ethiopia $5^{\text {th }}$ September 2020

Source: Ethiopian Public Health Institute (2020)

Figure I COVID-19 data in Ethiopia.

to be $113,112,004$. Out of this, around $50.1 \%$ is youth. ${ }^{17}$ According to a report by the Ethiopian Ministry of Health, $67 \%$ of the COVID-19 infected age group is between 20 and 40 years old. This is because people in this range of age are highly mobile during the pandemic. They not only became apt to acquiring the virus but also aggravated the transmission rate.

The pandemic highly affected the Ethiopian economy. Agriculture, which accounts for $33.3 \%$ of the GDP, may reduce from $-0.8 \%$ to $-2.4 \%$; the industry, which accounts for $28.1 \%$ of the GDP, may reduce from $-8.5 \%$ to $-25.5 \%$; and the service sector, which accounts for $39.8 \%$ of the GDP, may reduce from-7.8 to $-23.4 \% .^{11,12,28}$ This economic slowdown severely affects especially poor. In the best-case scenario, the pandemic is expected to reduce the Ethiopian economy by $6.5 \%$ in the first quarter of the next Ethiopian fiscal year 2020/21. In the worst-case scenario, the pandemic may reduce the GDP by $16.7 \% .^{12}$ The economic impact the COVID-19 pandemic entailed affected not only the previously unemployed and already at-risk groups but also private employees, self-employed, informal operators, manufacturing, construction, trading, retail, hospitality, and tourism sectors. Studies ${ }^{25,30}$ revealed that, at a base scenario, globally 1.6 to 2.4 million and in worstcase scenario 3.2 to 4 million workers may lose their jobs due to the COVID-19 pandemic. In Ethiopia, 1.5 million private employees and 3.1 million self-employed workers are affected by the pandemic. ${ }^{12}$ In similar expression, the official poverty line shows that the pandemic would double the poverty rate from $22 \%$ to $48 \%$ of the population. Sixty-one percent of employment in construction, hospitality, restaurants, hotel sectors would be dropped. The remittances would be reduced by $40 \%$ (nearly \$570-850 million) due to job losses of the diaspora. ${ }^{2,11,29}$ Schools have been closed in Ethiopia since 16 March 2020 and 26 million children are staying at home. This stay-athome imposition exposed children to depression. ${ }^{28,33}$ About 26 million Ethiopians live below the food poverty line and around 23 million live below the absolute poverty line. For instance, around $90 \%$ of vegetables and other horticultural food products are supplied through the informal food market for Ethiopian urban centers $^{31}$ whose movement has been stopped during the pandemic. Because of the pandemic, the above-mentioned population faces the highest risks and vulnerability persistently.

The COVID-19 pandemic posed unprecedented sociocultural challenges particularly to the country where social gathering and sociocultural ceremonies are parts of the daily life. ${ }^{31}$ In Ethiopia, social gatherings are very common. People often come together for coffee ceremonies, weddings, burials, weekly and monthly gatherings of "Idir" local language term which stands for a social network (social group to help out members during loss of family members) and "Iqub" another form of indigenous social network (social group contribute a fixed amount of money from members and giving the sum to a member, every member receiving the sum turn by turn either daily, weekly or monthly basis). The State of Emergency (SoE) banned such socio-cultural gatherings to alleviate the pandemic transmission. ${ }^{6}$ This resulted in sociocultural crises and psychosocial trauma to the sociality. Furthermore, sociocultural disconnections untimely worsened the living conditions of the society. Homeless individuals and street children exposed to the most diversified socioeconomic risks. They are living 'above the dead and below the living".

\section{Ethiopian Public Administration Responses to COVID-19 Pandemic}

The Federal Ministry of Health prepared COVD-19 pandemic National Preparedness and Response Plan earlier to the outbreak of the COVID-19 pandemic in Ethiopia. ${ }^{23}$ The plan was made known to the public after the first COVID-19 case was reported on 12th March 2020. The SoE was declared based on the Federal Democratic Republic of Ethiopia (FDRE) Constitution art. 93(2) ${ }^{10}$ on 8th April 2020, valid for five months and to be extended if need be. ${ }^{6}$ The declaration prohibited gatherings of more than four individuals; downsized the number of travelers on public and private transport by $50 \%$ of their seating; reduced the seating capacities of the Ethio-Djibouti light trails to $25 \%$; sanctioned visits of prisoners in prisons and suspects at police stations; banned public entertainment sites (concerts, cinemas, and theaters); and closed borders except for cargo transport. Besides, the declaration also prohibited 
house renters from increasing rent and evicting renters. In addition, it imposed on the public to take all safety measures (wearing mask, washing hands, using sanitizers, and keeping distance) advised by the Ministry of Health. ${ }^{6,23}$

People were advised to stay at home (contagion), 50\% of employees of the public sectors were granted forced to work from home with full pay. ${ }^{4}$ For instance, $64 \%$ of the staff of the Prime Minister's office were working from home. The 6th National election was postponed and the service sectors were lockdown. ${ }^{6,23}$ Manufacturing sectors downsized their operations and some factories started manufacturing Personal Protection Equipment (PPE) such as Hawassa industrial park. Furthermore, the government provided a floating fund of $\$ 44.2$ million to the banking industry aimed to reverse the financial bankruptcy the COVIDpandemic entailed and establish the National COVID-19 Emergency Response Fundraising which collected \$50Mn as of May 2020. The Ethiopian Prime Minister, Dr. Abiy Ahmed, called for debt relief (reductions in principal or extensions of maturity), and restructuring plan as a global approach and strategy to respond to coronavirus pandemic effectively. The prime minister requested the developed counties to cooperate African countries in their effort to alleviate the consequences of the pandemic.

\section{Success Stories of Ethiopian Public Administration COVID-19 Responses}

Developing economies with less developed health systems are likely to face more significant challenges and remain vulnerable to the COVID-19 pandemic compared to advanced economies. ${ }^{27}$ Despite the resource limitations and drawbacks, the overall performance of the Ethiopian government in the prevention and control of the pandemic is effective. It achieved better results in resource mobilizations, collaboration, and interoperability among line ministries and of government departments, partners, local networks, donors, and all concerned stakeholders. The estimated COVID-19 pandemic crises in Ethiopia and the reality on the ground is quite different compared to the pandemic havoc entailed globally. The government established different ad-hoc steering committees at all government tires. The National Ministerial Committee steering ad-hoc committee (chaired by the deputy prime minister) was established at the Federal level. ${ }^{35}$ The Federal Civil Service offices, the regional equivalents, and local governments ${ }^{7}$ established similar committee to prevent and control the pandemic, provide public awareness and education, provide up-to-date information, and avail control and prevention mechanisms to the general public. The committee formation was not limited to the public sectors but also to social organizations such as religious institutions and youth associations also established ad-hoc committee for the pandemic prevention and control. These organizations and associations were also working jointly with the government by establishing an interdependent pandemic prevention and control committee at grassroots levels. These were locally contextualized policy responses unlike those of most of African countries. $^{14}$ The government has been televised major religious events, and commemorations.

Currently, Ethiopia has more than 24 COVID-19 testing center laboratories have been functioned which can test more than 19,000 samples a day. The government has licensed PPE manufacturing industries and COVID-19 testing kit plant which begun its production in the first weeks of September 2020 both for local and regional market. At the beginning of the pandemic, all COVID-19 suspected samples of Ethiopia were tested in South Africa. Since March 2020 most public Universities are producing PPE (hand rub sanitizers, face masks, mechanical and automatic handwashing facilities) and some are conducting scientific investigation to find vaccine for COVID-19. The government established COVID-19 temporal hospitals and treatment centers. ${ }^{23,35}$ In this regard, the Millennium hall, which is the largest multipurpose hall in the country, was changed into a COVID-19 treatment center and has been serving as temporal COVID-19 hospital new arrangement among others (see, Figure 2B).

Though the Ethiopian airline reported a $\$ 550 \mathrm{Mn}$ loss ${ }^{15}$ due to the global sharp decline from 4.5 billion airline passengers in 2019 to 2.2 billion 2020. ${ }^{19,27}$ Because of COVID19 pandemic, it is serving as the regional (African) flagship to COVID-19 pandemic response. The airline played a leading role in cargo transportations and COVID-19 medical equipment, PPE, and other facilities shipment during the pandemic across Africa and the rest of the world. During the pandemic, the airline changed passengers' planes into cargo services (see Figure 2A).

Moreover, the government of Ethiopia plays a significant diplomatic relationship in responding to COVID-19 pandemic responses to the country and Africa as well. In this regard, the government secured various bilateral and/or multilateral collaborations and financial assistance to increase the national public health preparedness and pandemic control capacities. The World Bank allocated a total of $\$ 82.6 \mathrm{Mn}$ with half loan and half grant, \$14Mn from Japanese government aid to ecosocial development, \$70Mn million concessional loans from the government of the Republic of Korea to COVID-19 


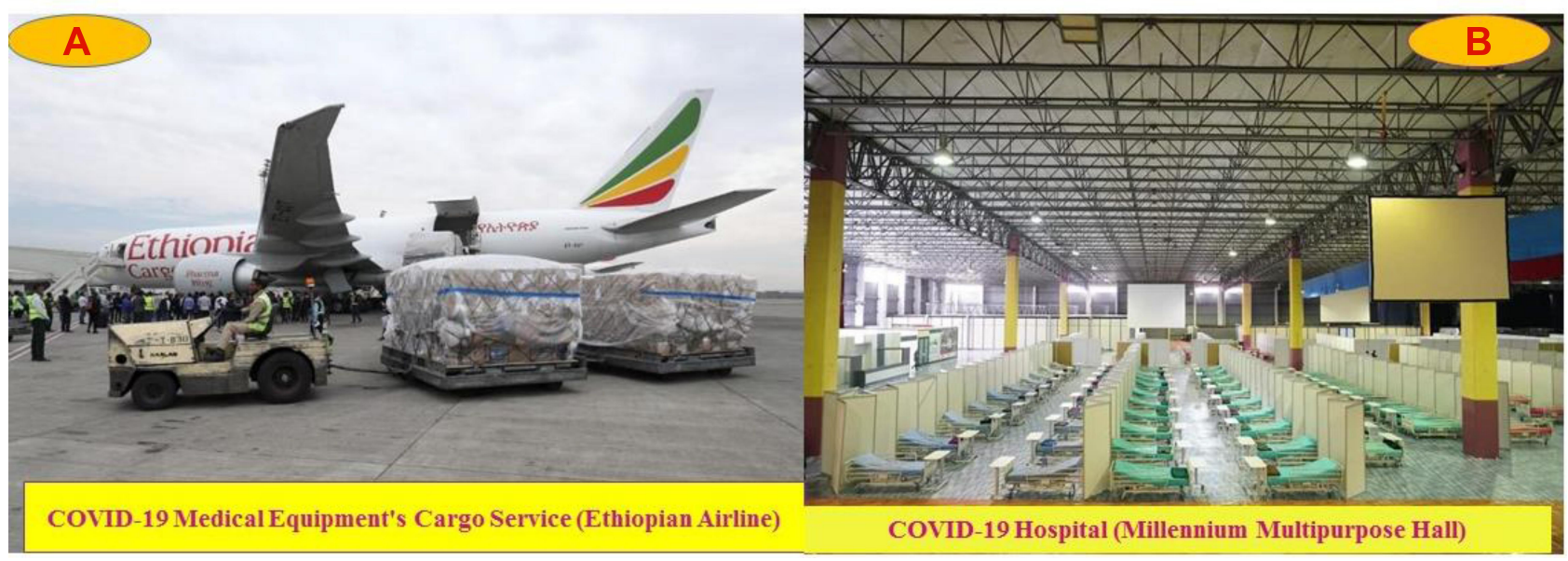

Figure 2 Ethiopian Airline Cargo Services (A) and new COVID-19 hospital in Ethiopia (B) Millennium Multipurpose Hall.

emergency crises national response. ${ }^{16}$ Jack Ma \& Alibaba Foundation, Bill \& Melinda Gates Foundation, and Byte Dance \& Tik Tok have generously donated COVID-19 testing kits, PPE materials, and financial support which would worth millions of USD. The government also got $€ 10$ million to support the preparedness and response plan to the pandemic, African development bank provided a regional (continental) floating fund grants, European Humanitarian Aid and Civil Protection (ECHO), United Nation's Central Emergency Response Fund (CERF), Korea International Cooperation Agency (KOICA), and German Development Cooperation. These all bilateral, and multilateral supports are the result of effective foreign and diplomatic relationships. ${ }^{16}$

\section{Public Administration's Response Limitations of Ethiopia}

Public administration is always full of uncertainties, particularly in policy decisions. Uncertainties exist regarding the duration and termination of policy decisions while public administration is experiencing a surge of a policy change aimed at reducing immediate societal threats. ${ }^{30}$ The Ethiopian government closed schools as a response to mitigating the spread of the COVID-19 pandemic. However, prolonged closures brought risks to the education and the wellbeing of children, families, teachers, and communities. School closures seriously affected a lot of food-insecure children who were beneficiaries of school feeding programs in Addis Ababa. The government did not provide an alternative platform to address the needs of the additional vulnerable children and families added due to the pandemic. The government also introduced distance learning using television, radio, and the internet (online education). However, access to television, radio, and internet to children is unaffordable especially for those living in the countryside of Ethiopia (where more than $85 \%$ of the population lives in rural areas with no access to electricity, TV, radio, and internet). Therefore, these measures of the government were impractical and rhetoric.

The government was not effective in the proper implementation of SoE. The ruling party held political meetings in different parts of the country against the SoE embargo of meeting. As $50 \%$ of seats were reduced in public and private transport services, cities like Addis Ababa faced serious lack of transport services. The government failed to provide alternative transportation facilities. Public holiday marketing during Christian Easter and Muslim Eid alFitr or EID were highly crowded like previous years. The government's enforcement of SoE such as two-meter physical distance at the market places was not practical. Again, due to political instability, there were popular demonstrations in different parts of the country such as in Tigray, Oromia, and Addis Ababa. These demonstrations were the other main channels for the transmission of the COVID-19 pandemic. ${ }^{26}$ Most of these demonstrations were not followed with legal procedures. The effort made by the government to proper implementation some of $\mathrm{SoE}$ declarations was ineffective.

\section{Essentialities of Social Organizations in Ethiopia to Respond to COVID-19 Crises}

Most SoE declaration statements banned movements and economic activities. These restrictions and lockdown were not favored by those who could not afford to stay at home. ${ }^{26}$ On the other hand, the government 
of Ethiopia cannot afford to provide cash or non-cash transfers as social protection benefits to those vulnerable groups. Such situations, social organizations played important roles in providing help to the needy during the pandemic (see Figure 3). Social capital and social organization have significant importance in the life of all Ethiopians. ${ }^{31}$ Ethiopians have a long history of social cohesion, social life and social economy, social gathering to commemorate different social events, and a unique social harmony commensurate that magnifies the social solidarity to promote the values of people's philosophy. They are known with unique social institutions to share common social values both in happiness and grieves. Social organizations in Ethiopia might be formed in different arrangements such as religious, neighborhoods, youth, cultural, and traditional institutions (Iqub and Edir), voluntary, school peer networks, and so forth. All social organizations commonly share the principles of social solidarity and members' participation to mutually benefit by sharing socioeconomic burdens. ${ }^{14}$ These social organizations play a significant contribution to support the vulnerable groups. These organizations played a paramount contribution to averse the socioeconomic crises of the pandemic in Ethiopia and it were an interactive with the government policy responses.

Prime Minister Abiy understood the contribution of social organizations to reduce the socioeconomic crises of COVID0-19 on the most vulnerable groups. He introduced an initiative called "Sharing the Meal", ie, feeding a neighbor once a day during the pandemic. The initiative was accepted and implemented by individuals and different social organizations. The initiative played an extensive contribution to reducing the crises to the COVID-19 pandemic entailed on the extremely vulnerable groups in providing food and nonfood services. More than 4.5 million vulnerable individuals benefited from this initiative providing support for vulnerable groups through religious organizations, neighborhood networks, youth, and voluntary association networks providing support for vulnerable groups (see Figure 3).

Furthermore, since the COVID-19 pandemic outbreak, private organizations, business firms like hotels and individuals, and public contributed to alleviate the consequences by availing their wealth and services for free (see Box 1)

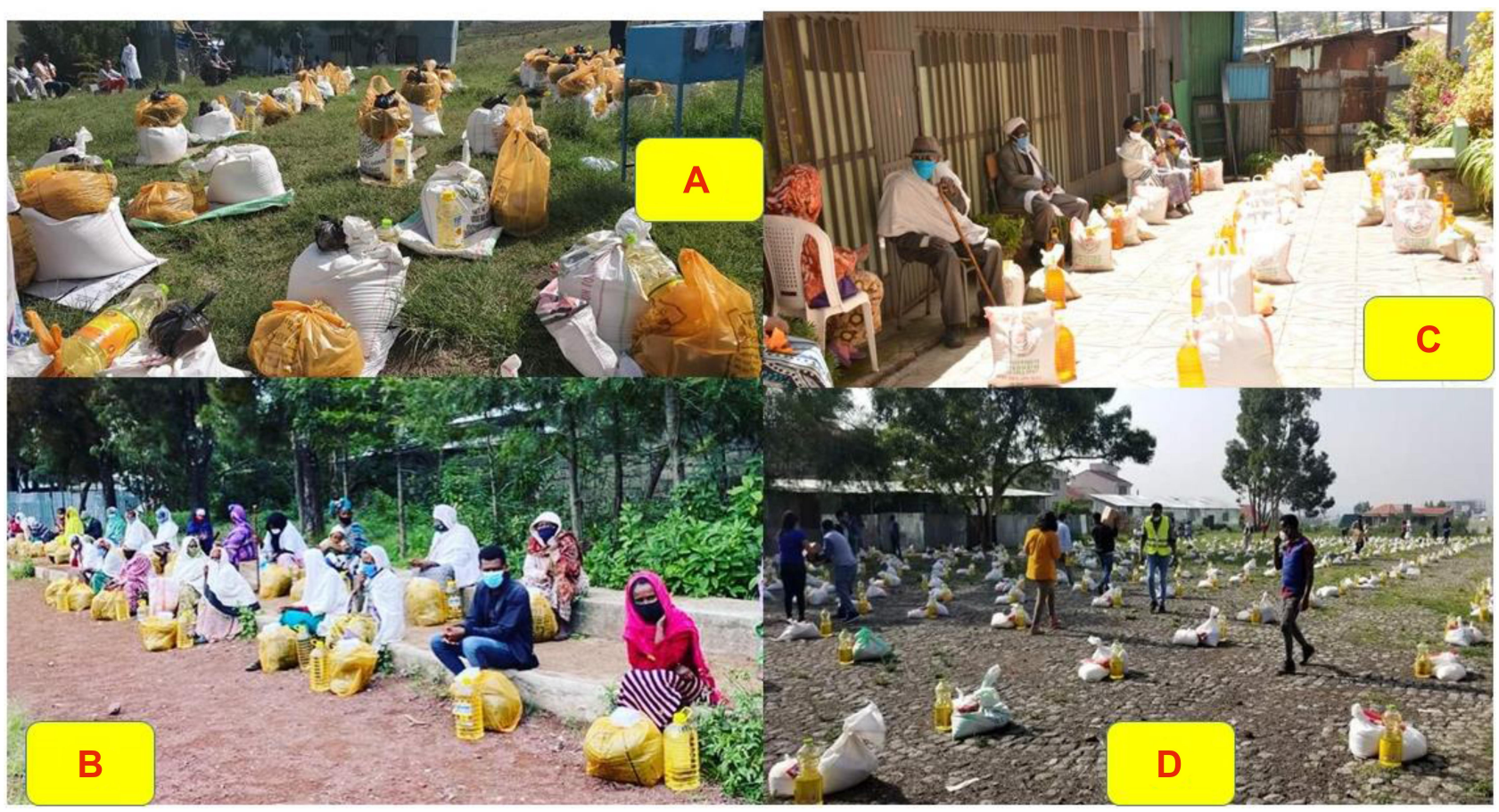

Figure 3 Social organizations; (A and B) religious network support, (C) Neighborhood network support and (D) youth and voluntary association support to reduce the COVID-19 socioeconomic crises. 


\section{Box I Social Solidarity}

\section{Case_I: Social Solidarity Illustration in Ethiopia}

Mr. Khalid Naser is a young Ethiopian who lives in Addis Ababa, Ethiopia. He had done a unique tremendous contribution to reduce the COVID-19 socioeconomic crises particularly to the homeless street individuals whose living rooms were the street of Addis. Mr. Kalid changed his living house into residence for 100 homeless street individuals since March 2020. He covered expenses of these 100 new family members since the COVIDI 9 pandemic outbreak in the country. He did not share the extra he had but what he had. For his contribution, Mr. Kalid was recognized on the "Bego Sew Yearly Award" held on the 6th September 2020 and at the 8th annual special award of 'Ye Ametu Bego Sew' (The Benevolence Person of the Year of 2020 G.C)"

below. This evidenced the imperatives of social responsibilities to minimize the risk of the pandemic.

\section{Conclusion}

The COVID-19 global pandemic posed unprecedented socioeconomic havoc to the whole world in general and Ethiopia in particular. Developing economies' crises estimations were dreadful because of their poor health infrastructures and worsened socioeconomic inequalities even before the pandemic outbreak. The pandemic slowed down all economic activities (except ICT sector). It also posed sociocultural and psychological challenges. Still, the ending-up period is not yet known and its spreading is not under control, and uncertainties are still shooting up. The overall crises of the pandemic both in developed and developing economies was estimated to be global issue of the $21 \mathrm{stC}$.

Governments around the world provided different policy responses. In this regard, the government of Ethiopia took policy responses. The government achieved remarkable success in preventing and controlling the pandemic and accomplished effective diplomatic relationship for the country and Africa COVID-19 pandemic responses. On the other hand, poor institutional setups/systems and capacity constraints failed to execute the COVID-19 policy responses properly including the SoE and other policy measures. Social organizations such as religious, neighborhoods, youth, voluntary, traditional institutions, and school peer networks played a paramount role in reducing the socioeconomic and psychocultural crises of the pandemic. Social organizations have been considered as the best model of social solidarity platform of the COVID-19 crises response hub at grassroots levels. Social organizations' imperativeness played an interactive and interwoven interface with the state policy responses in reducing socioeconomic crises and minimalization of the psychocultural havoc of the coronavirus. The government should emphasize on institutionalization of social organizations and strengthening their capacities through different program packages to enable them contributing for the development endeavors of the country.

\section{Acknowledgment}

I acknowledged my friends at different Federal Ministry Offices who provided pertinent data to the study; the anonymous reviewers for their insightful comments that strengthened the quality of the paper. I thank Tagel Elias (PhD) for his language editorial work, and the ClinicoEconomics and Outcomes Research editorial staff for their unreserved cooperation.

\section{Disclosure}

The author reports no conflicts of interest in this work.

\section{References}

1. Asian Development Bank (ADB). The economic impact of the COVID-19 outbreak on developing Asia, Asian development bank BRIEFS (2020), $\mathrm{N}^{\mathrm{o}}$. 128; March 6, 2020.

2. Associated Press (AP). Extreme poverty rises and generations sees future slip away (Meseret E. \& Anna C.); 2020. Available from: https://apnews.com/727c2dea29daed6e226b964f8caadfcf. Accessed August 20.

3. Baldwin R, Di Mauro BW. Economics in the time of COVID-19: a new eBook. VOX CEPR Policy Portal. 2020.

4. Boone L, Haugh D, Pain N, et al. Tackling the fallout from COVID-19. Economics in the Time of COVID-19. 2020;37.

5. Brief, Policy. The impact of COVID-19 on women. United Nations entity for gender equality and the empowerment of women (UN Women). United Nations Secretariat; 2020. Available from: https:// www.UN.women.org/-/media/headquarters/attachments/sections/ library/publications/2020/policy-brief-the-impact-of-COVID-19-onwomen-en.pdf.

6. Council of Ministers. COVID-19 state of emergency proclamation No. 3/2020. Addis Ababa, Ethiopia; 2020.

7. Debela BK. The COVID-19 pandemic and the Ethiopian public administration: responses and challenges. Good Public Governance in a Global Pandemic. 2020:113.

8. Di Mauro BW. Macroeconomics of the flu. Economics in the Time of COVID-19. 2020:31.

9. Erixon F. The economic benefits of globalization for business and consumers. Eur Centre Int Political Econ. 2018.

10. The 1994 Revised Ethiopian Constituion; Federal Democratic Republic of Ethiopia Constitution; 1994.

11. Geda A. The macroeconomic and social impact of COVID-19 in Ethiopia and suggested direction for a policy response. Department of Economics, AAU. 2020a.

12. Geda A. The macroeconomic and social impact of COVID-19 in Ethiopia and suggested direction for a policy response. Department of Economics, AAU. 2020b.

13. Getaneh Y, Yizengaw A, Adane S, et al. Global lessons and potential strategies in combating COVID-19 pandemic in Ethiopia: systematic review. medRxiv. 2020.

14. Hartwich F, Isaksson A. Policy responses to COVID-19 supporting African industry through the COVID-19 pandemic. Vienna: United Nations Industrial Development Organization; 2020. 
15. Capital Newspaper: Ethiopian Airlines Loses $\$ 550$ million Revenue. Available from: http://www.capitalethiopia.com/capital/ethiopianairlines-loses-550-in-revenue/). Accessed September 1, 2020.

16. Ethiopian COVID-19 Realted Grant and Loan New. Available from: http://www.mofed.gov.et/news-and-updates. Accessed July 26, 2020.

17. The Ethiopian Population Structure. Available from: https://country meters.info/en/Ethiopia\#age_structure. Accessed July 15, 2020.

18. Global States Fragility Index. Available from: https://fragilestatesin dex.org/country-data. Accessed March 10, 2020.

19. International Air Transport Association (IATA). Restarting aviation following COVID-19; 2020.

20. Jansen BJ, Pooch U. A review of web searching studies and a framework for future research. JASIST. 2001;52(3):235-246. doi:10.1002/10974571(2000)9999:9999<::AID-ASI1607>3.0.CO;2-F

21. Katper NK, Tunio MN, Hussain N, Junejo A, Gilal FG. COVID-19 crises: global economic shocks vs Pakistan economic shocks.

22. McKibbin W, Fernando R. The global macroeconomic impacts of COVID-19: seven scenarios. Asian Economic Papers. 2020:1-55.

23. Ministry of Health Ethiopia. National comprehensive COVID19 management handbook; 2020. Available from: https:/extranet.who. int/goarn/national-comprehensive-covid19-management-handbook.

24. Naudé W. Industrialization under medieval conditions? Global development after COVID-19. No. 13829. IZA Discussion Papers. 2020

25. Parry BR, Gordon E. The shadow pandemic: inequitable gendered impacts of COVID-19 in South Africa. Gend Work Organ. 2020. doi:10.1111/gwao. 12565
26. Pleyers G. The Pandemic is a battlefield. Social movements in the COVID-19 lockdown. J Civ Soc. 2020:1-18.

27. Shrestha N, Shad MY, Ulvi O, et al. The impact of COVID-19 on globalization. One Health. 2020;11:100180. doi:10.1016/j. onehlt.2020.100180

28. United Nations International Children's Emergency Fund. Socioeconomic impacts of COVID-19: UNICEF Ethiopia. 2020.

29. United Nations. Socioeconomic impact of COVID 19 in Ethiopia. United Nations, Ethiopia Addis Ababa: One UN Assessment; 2020.

30. Weible CM, Nohrstedt D, Paul Cairney DP, et al. COVID-19 and the policy sciences: initial reactions and perspectives. Policy Sci. 2020;53 (2):225-241. doi:10.1007/s11077-020-09381-4

31. Weldesilassie Alebel B, Woldehanna Tasew W. The economic implications of COVID-19 in Ethiopia and policy measures. Policy Studies Institute; 2020.

32. Witt MA. De-globalization: theories, predictions, and opportunities for international business research. J Int Bus Stud. 2019;50 (7):1053-1077. doi:10.1057/s41267-019-00219-7

33. World Health Organization. Coronavirus disease 2019 (COVID-19): situation report, 86. 2020.

34. Yin RK. Qualitative research from start to finish. Guilford publications; 2015.

35. Zikargae MH. COVID-19 in Ethiopia: assessment of how the Ethiopian government has executed administrative actions and managed risk communications and community engagement. Risk Manag Healthc Policy. 2020;13:2803. doi:10.2147/RMHP.S278234
ClinicoEconomics and Outcomes Research

\section{Publish your work in this journal}

ClinicoEconomics and Outcomes Research is an international, peerreviewed open-access journal focusing on Health Technology Assessment, Pharmacoeconomics and Outcomes Research in the areas of diagnosis, medical devices, and clinical, surgical and pharmacological intervention. The economic impact of health policy and health systems organization also constitute important areas of coverage. The manuscript management system is completely online and includes a very quick and fair peer-review system, which is all easy to use. Visit http://www.dovepress.com/testimonials.php to read real quotes from published authors. 